\title{
Coronary Artery Disease in End-Stage Renal Disease : Risk Factors and Treatment Strategies \\ -from the Invitation Lecture of 44th Congress of Japanese Society for Dialysis Therapy (JSDT) -
}

\author{
Sarah S. Prichard, M. D., F. R. C. P. (C) \\ Professor of Medicine, McGill University Royal Victoria Hospital-Nephrology Division
}

Dialysis and transplantation have afforded patients with end-stage renal disease effective renal replacement therapy. Advances in the therapies have included a better understanding of adequacy requirements, technological advances, and new pharmacological therapies such as Erythropoietin. Consequently, the number of patients initiating renal replacement therapies has grown around the world.

Cardiovascular events remain the most common cause of death amongst patients with end-stage renal disease. In most registries throughout the world, it is reported that between 35 and $50 \%$ of the mortality is attributable to a cardiovascular event $^{1 \sim 4)}$. Compared to the general population, dialysis patients have a tenfold increased risk for annual mortality from cardiovascular disease. This increased risk is particularly dramatic for endstage renal disease patients under the age of 45 , but even in those patients over 85 years of age, there is a greater than 4 fold increase in the risk of cardiovascular death for dialysis patients ${ }^{5)}$.

The types of cardiovascular disease found in patients with end-stage renal disease include coronary artery disease, left ventricular hypertrophy, hypertension, congestive heart failure, peripheral vascular disease, valvular disease and a variety of others including arrhythmias and infiltrative disease. This paper focuses on risk factors and potential treatment strategies for coronary artery disease (CAD) in patients with chronic renal insufficiency.
Table 1 Risk Factors for Coronary Artery Disease

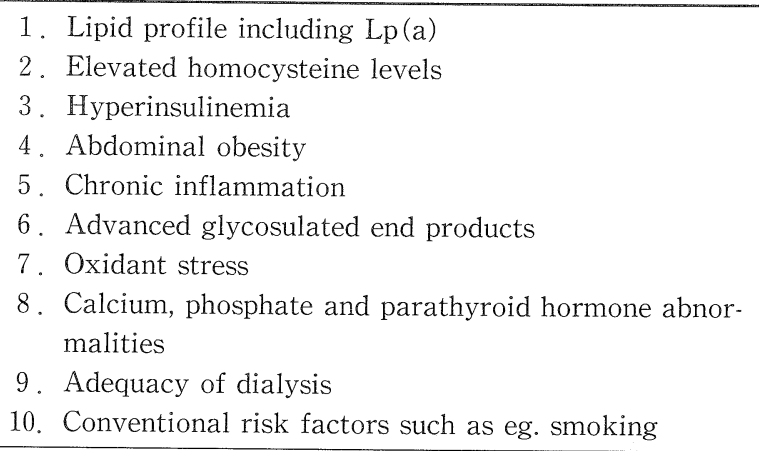

Amongst the various cardiovascular abnormalities in ESRD patients, coronary artery disease is the most important cause of morbidity and mortality. It is often confounded by the presence of left ventricular hypertrophy and may express itself as congestive heart failure, but as an underlying etiology for cardiac mortality, it is the predominant pathology. Furthermore, it is known that patients who initiate renal replacement therapy with preexisting ischemic heart disease have a significantly worse prognosis than those without ischemic heart disease $^{6)}$. Thus, it is incumbent on the nephrology community to develop strategies for assessing and treating risk factors for ischemic heart disease both in the pre-dialysis phase and the dialysis phase of a patient's course.

\section{Risk for Coronary Artery Disease}

Table 1 summarizes known risks for coronary

\footnotetext{
Sarah S. Prichard Professor of Medicine, McGill University Royal Victoria Hospital-Nephrology Division 687 Pine Avenue West Montreal, Quebec H 3 A 1 A 1
}

Tel : (514)842-1231 ext. 4672 Fax : (514)982-0897 Email : sarahp@medusa.medcor.mcgill.ca 
artery disease in patients with end-stage renal disease.

\section{Lipid Abnormalities in the End-Stage Renal Disease}

Dyslipidemia is a well recognized complication of patients with end-stage renal disease. The lipid abnormalities differ for those patients undergoing hemodialysis compared to those on peritoneal dialysis $^{7 \sim 9)}$. Specifically, patients on hemodialysis characteristically have low HDL levels, elevated triglycerides, measurable oxidized LDL cholesterol, elevated Lp(a), and normal LDL cholesterol and apoliprotein B levels. In contrast, patients on peritoneal dialysis usually have an elevated LDL cholesterol and APO B protein, elevated triglycerides, reduced HDL cholesterol, elevated $L p(a)$ and measurable oxidized LDL. Thus, those patients on peritoneal dialysis have a more atherogenic profile for lipoproteins than patients on hemodialysis.

The evidence is overwhelming that the treatment of lipid abnormalities, particularly the reduction of LDL cholesterol, is effective in improving outcomes with respect to cardiovascular disease in the nonuremic population ${ }^{10)}$. Equivalent data is not available for the dialysis population. Current recommendations in Canada are that LDL cholesterol be reduced to less than $2.5 \mathrm{mmol} / \mathrm{L}$ in patients with known pre-existing coronary artery disease (secondary prevention) and to less than $3.5 \mathrm{mmol} / \mathrm{L}$ in others. However patients with 3 known risk factors for coronary artery disease are presumed to have subclinical disease and recommendations thus attribute those patients to a secondary prevention treatment strategy. Given the multiple risks that uremia imposes on our patient population, and given the known high prevalence of the disease, a reasonable argument can be made that all patients with chronic renal insufficiency should be treated for secondary prevention with respect to lipids.

\section{Homocysteine}

In the non-uremic population, elevated homocysteine levels have been associated with a higher mortality rate after acute myocardial infarction ${ }^{11}$.
It is known that patients on dialysis and transplant patients have significantly elevated homocysteine levels and that these high levels are associated with cardiovascular events ${ }^{12 \sim 16)}$. These elevations of homocysteine cannot be attributed to a difference in the distribution of phenotype for methylenetetrahydrofolate between uremic and non-uremic individuals. Patients on renal replacement therapies are resistant to therapy with folate and $\mathrm{B} 12^{17)}$, which in the non-uremic population can usually normalize the plasma levels of homocysteine.

\section{Hyperinsulinemia and Abdominal Obesity}

Hyperinsulinemia is an independent risk factor for coronary artery disease ${ }^{18)}$. Abdominal obesity and insulin resistance with high insulin levels are often associated and is characteristic of patients with type II diabetes. Renal failure is known to lead to insulin resistance and thus hyperinsulinemia is frequent in patients with renal insufficiency ${ }^{19)}$. Android, or abdominal obesity, with insulin resistance is associated with a number of lipoprotein abnormalities including hypertriglyceridemia, elevated Apolipoprotein B levels and reduced HDL cholesterol which when coupled with insulin resistance constitutes an important risk for the development of coronary artery disease. At least one report has shown that peritoneal dialysis increases abdominal obesity which may further exacerbate the prob$\operatorname{lem}^{20)}$.

\section{Chronic Inflammation}

Ridker reported that elevated C-reactive protein was an independent risk for myocardial infarction in the non-uremic population ${ }^{21)}$. Dialytic therapy, particularly hemodialysis, induces a state of chronic inflammation in our patient population ${ }^{22)}$. Bergstrom et al reported C-reactive protein as a more powerful predictor of mortality than albumin. There is also an association between $\mathrm{C}$-reactive protein and elevated $\mathrm{Lp}$ (a) levels which may be important in the evolution of coronary artery disease $^{23)}$. 


\section{Advanced Glycosolution End Products (AGE's)}

Advanced glycosolution end products deposit in the vessels of patients with diabetes and in the peritoneum of patients on peritoneal dialysis. The excretion of AGE's are impaired as the renal function deteriorates. It may be important in contributing to oxidant stress, although the direct deposition into vessels in uremia unrelated to diabetes remains an uncertain, but potential risk for the development of atherosclerosis.

\section{Oxidant stress}

The ingestion of a high anti-oxidant diet is associated with less atherosclerotic disease in the general population ${ }^{24)}$. Uremia is associated with a high rate of formation of oxidants and may be another risk factor for the development of atherosclerosis $^{25)}$. Oxidation of LDL is increased in uremia and is important in the formation of foam streaks.

\section{Calcium, Phosphate and Parathyroid Hor- mone}

Hemodialysis patients have been found to have markedly elevated cardiac calcification when measured using an electron beam CT technique ${ }^{26)}$. Furthermore, the coronary calcium score for patients on hemodialysis is dramatically higher than those levels found in patients with coronary artery disease. These high levels of cardiac and coronary calcium increases substantially with age and correlates with a long known phenomenon of dense calcifications seen in coronary as well as peripheral vessels of patients with uremia. More recently in the USRDS, hyperphosphatemia has been found to be associated with a higher general mortality in patients on hemodialysis ${ }^{27)}$. Specifically cardiac mortality is significantly increased in patients with phosphate levels greater than $6.5 \mathrm{mg} / \mathrm{d} l^{28)}$. This implicates the importance of abnormalities of calcium and phosphate in the evolution of calcific atherosclerosis. Foley et al have reported that patients with hypocalcemia and elevated alkaline phosphatase (and therefore presumably have ele- vated parathyroid hormone levels) have a significant increase risk for de novo ischemic heart disease $^{29)}$.

\section{Adequacy}

Patients with improved adequacy of dialysis have a reduction in their overall mortalities and this includes a significant reduction in cardiovascular mortality.

\section{Conventional Risk Factors}

Conventional risk factors such as diabetes, hypertension, positive family history and smoking have all been demonstrated to be relevant to increased risks of CAD in patients with chronic renal insufficiency. The cessation of smoking is particularly noteworthy since it is a modifiable risk factor for these patients ${ }^{30)}$.

\section{Risk Factors : Summary}

In summary, patients with chronic renal insufficiency have multiple risk factors for the development of coronary artery disease. Although the exact prevalence of coronary artery disease is not known, the US CASE MIX study reported that $40 \%$ of hemodialysis and peritoneal dialysis patients have clinical coronary artery disease ${ }^{31}$. In the 1998 Canadian Registry, coronary artery disease was present in $23.1 \%$ of the diabetic and $5.2 \%$ of the non-diabetic patients under the age of 45 . In those over the age of 45 , this increased to $56.6 \%$ of the diabetics and $45.8 \%$ of the non-diabetics ${ }^{3)}$. In a detailed study of 400 dialysis and transplant patients followed at the Royal Victoria Hospital at McGil University, in May 1998, there was a prevalence of coronary artery disease of $60 \%$ in the dialysis population and $18 \%$ in the transplant population. When one combines the high risk profile of patients with chronic renal insufficiency together with a known high prevalence of the disease, it seems reasonable to adopt a treatment rtrategy for secondary prevention. 


\section{Current Treatment Practices for Ischemic Heart Disease}

Data on current treatment practices for ischemic heart disease are sketchy in the literature. Based on the USRDS report in 1998, approximately $15 \%$ of patients on peritoneal dialysis and $8 \%$ of patients on hemodialysis were receiving anti-lipid therapy. In this same population, at least $40 \%$ of the patients had known coronary artery disease and the vast majority would have significant dyslipidemia. Thus, the current rate of treatment for dyslipidemia in the United States would appear to be less than that which would be recommended if secondary prevention strategies were used.

In a single centre study at the Royal Victoria Hospital, McGill University, Canada, prevalent patients on May 15th, 1998 were reviewed with regard to their coronary artery disease status and current treatments. Results are shown in Table 2. A total of 400 patients were reviewed which constituted the entire ESRD population at that institution. Patients who had died between May 15th and the date of chart review, new transplants and those with prolonged hospital courses were excluded. The latter two groups were excluded because their treatment on May 15, 1998 would likely not represent their usual treatments. Of those 400 patients, 147 were dialysis patients and 88 or $60 \%$ had ischemic heart disease documented in the chart. Forty-five of 208 transplant patients, or $18 \%$, had coronary artery disease.

A review of their current medications revealed that $18 \%$ of the dialysis patients with ischemic heart disease were receiving an $\mathrm{HMG}$ CoA reductase inhibitor, 38\% were receiving aspirin and 1\% were receiving folic acid in excess of $1 \mathrm{mg} /$ day. Amongst the transplant population, $38 \%$ of those with ischemic coronary artery disease were receiving an HMG CoA reductase inhibitor, $42 \%$ were receiving aspirin and none were receiving folic acid in excess of $1 \mathrm{mg} /$ day. Therefore, consistent with the USRDS data, it would appear that the dialysis and transplant population in this centre were not receiving treatments which one would consider to be appropriate in the non-uremic population. No explana-
Table 2 Treatment of Coronary Artery Disease Royal Victoria Hospital, Montreal, Canada

\begin{tabular}{lcc}
\hline & Dialysis* & Transplant* \\
\hline Number of patients & 147 & 253 \\
Number of patients with CAD & 88 & 45 \\
$\%$ of patients with CAD & $60 \%$ & $18 \%$ \\
$\%$ of patient with CAD on : & & \\
- Antilipid therapy & $18 \%$ & $38 \%$ \\
- ASA & $38 \%$ & $42 \%$ \\
- Folic Acid $>/ \mathrm{mg} / \mathrm{d} l$ & $1 \%$ & $0 \%$ \\
\hline
\end{tabular}

* Prevalent patients on May 15, 1998

tion for these findings could be ascertained from the current study.

\section{Conclusion}

Patients with chronic renal insufficiency and endstage renal disease have a high incidence of coronary artery disease and have many risk factors which predispose them to the disease. Treatment strategies need to be developed which will reduce this risk profile for these patients. Based on data from the USRDS and from a single centre study in Canada, it appears that nephrologists have not embraced the concept of treatment strategies for secondary prevention of coronary artery disease. There is no evidence to indicate that such strategies are effective in reducing coronary artery disease in this patient population, but until such time as the evidence is forthcoming, it would seem reasonable to give renal insufficiency patients the benefit of treatments known to be efficacious in the nonuremic population. Further studies are needed in the uremic population to assess the efficacy of such treatment strategies.

\section{References}

1) Raine AEG : The EDTA Registry Committee. Combined report on regular dialysis and transplantation in Europe, XXII, 1991. Nephrol Dial Transplant 2 : 7-35, 1992

2) US Renal Data System (USRDS) 1991. Annual data report. Survival probabilities and causes of death. Bethesda, MD : National Institutes of Health, National Institutes of Diabetes and Digestive and Kidney Disease, 31-40, 1991

3) Annual Report 1998, Volume 1: Dialysis and Renal Transplantation, Canadian Organ Replacement 
Register, Canadian Institute for Health Information, Ottawa, Ontario, June 1998

4) U.S. Renal Data System : USRDS 1997 Annual Data Report, National Institutes of Health, National Institute of Diabetes and Digestive and Kidney Diseases, Bethesda, MD, 1997

5) Foley RN, Parfrey PS, Sarnak MJ : Epidemiology of cardiovascular disease in chronic renal disease. J Am Soc Nephrol 9 : S16-S23, 1998

6) Parfrey PS, Foley RN, Harnett JD, Kent GM, Murray D, Barre PE : Outcome and risk factors of ischemic heart disease in chronic uremia. Kidney Int $49: 1428-1434,1996$

7) Avram MM, Fein PA, Antignani A, et al. : Cholesterol and lipid disturbances in renal disease: The natural history of uremic dyslipidemia and the impact of hemodialysis and continuous ambulatory peritoneal dialysis. Am J Med 87 : 5N-55N, 1989

8) Sniderman A, Cianflone K, Kwiterovich PO, Hutchinson T, Barre P, Prichard S : Hyperapobetalipoproteinemia in patients with chronic renal failure treated with chronic ambulatory peritoneal dialysis. Atherosclerosis 65:257-264, 1987

9) Attman POA, Samuelsson OG, Moberly J, Johansson AC, Lungman S, Weiss LG, Knight-Gibson C, Alaupovic $\mathrm{P}$ : Apolipoprotein $\mathrm{B}$-containing lipoproteins in renal failure: The relation to mode of dialysis. Kidney Int 55: 1536-1542, 1999

10) Gould AL, Rossouw JE, Santanello NC, et al. : Cholesterol reduction yields clinical benefit. Impact of Statin Trials. Circulation 97 : 946-952, 1998

11) Nygard O, Nordrehaug JE, Refsum H, Ueland PM, Farstad M, Vollset SE: Plasma homocysteine levels and mortality in patients with coronary artery disease. N Engl J Med 337 : 230-236, 1997

12) Bachmann J, Tepel M, Raidt H, Riezler R, Graefe U, Langer K, Zidek W: Hyperhomocysteinemia and the risk for vascular disease in hemodialysis patients. J Am Soc Nephrol 6 : 121-125, 1995

13) Dennis VW, Robinson $\mathrm{K}$ : Homocysteinemia and vascular disease in end-stage renal disease. Kidney Int 50 : S11-S17, 1996

14) Bostom AG, Lathrop $L:$ Hyperhomocysteinemia in end-stage renal disease : Prevalence, etiology, and potential relationship to arteriosclerotic outcomes. Kidney Int 52:10-20, 1997

15) Moustapha A, Naso A, Nahlawi M, Gupta A, Arheart KL, Jacobsen DW, Robinson K, Dennis VW : Prospective study of hyperhomocysteinemia as an adverse cardiovascular risk factor in end-stage renal disease. Circulation 97 : 138-141, 1998

16) Vychytil A, Fodinger M, Wolfl G, Enzenberger B, Auinger M, Prischl F, Buxbaum M, Wiesholzer,
Mannhalter C, Horl WH, Sunder-Plassmann G : Major determinants of hyperhomocysteinemia in peritoneal dialysis. Kidney Int $53: 1775-1782,1998$

17) Bostom AG, Shemin D, Lapane KL, Hume AL, Yoburn D, Nadeau MR, Bendich A, Selhub J, Rosenber IH : High dose B-vitamin treatment of hyperhomocysteinemia in dialysis patients. Kidney Int 46:147-152, 1996

18) Gaudet D, Vohl MC, Perron P, Tremblay G, Gagné C, Lesiège D, Bergeron J, Moorjani S, Després JP : Relationships of abdominal obesity and hyperinsulinemia to angiographically assessed coronary artery disease in men with known mutations in the LDL receptor gene. Circulation 97 : 871-877, 1998

19) Fliser P, Pacini G, Engelleiter R, Kautzky-Willer A, Prager R, Franek R, Ritz E : Insulin resistance and hyperinsulinemia are already present in patients with incipient renal disease. Kidney Int 33: 1343-1347, 1998

20) Fernstrom A, Hylander B, Moritz A, Jacobsson H, Rossner $\mathrm{S}$ : Increase of intra-abdominal fat in patients treated with continuous ambulatory peritoneal dialysis. Perit Dial Intern 18: 166-171, 1998

21) Ridker PM, Glynn RJ, Hennekens $\mathrm{CH}$ : C-reactive protein adds to the predictive value of total and HDL cholesterol in determining risk of first myocardial infarction. Circulation 97 : 2007-2011, 1998

22) Wanner C, Zimmerman J, Quaschning T, Galle J : Inflammation, dyslipidemia and vascular risk factors in hemodialysis patients. Kidney Int 52 : S53S55, 1997

23) Stenvinkel $\mathrm{P}$, Heimbürger $\mathrm{O}$, Tuck $\mathrm{CH}$, Berglund $\mathrm{L}$ : Apo(a)-isoform size, nutritional status and inflammatory markers in chronic renal failure. Kidney Int $53:$ 1336-1342, 1998

24) Rimm EM, Stampfer MJ, Ascherio A, Giovannucci E, Colditz GA, Willett WC : Dietary intake and risk of coronary heart diseases among men. N Engl J Med 328: 1450-1456, 1993

25) Becker BN, Hemmelfarb J, Henrich WL, Hakim $\mathrm{RM}$ : Reassessing the cardiac risk profile in chronic hemodialysis patients: A hypothesis on the role of oxidant stress and other non-traditional cardiac risk factors. J Am Soc Nephrol 8: 475-486, 1997

26) Braun J, Oldendorf M, Moshage W, Heidler R, Zeitler E, Luft FC : Electron beam computed tomography in the evaluation of cardiac calcifications in chronic dialysis patients. Am J Kidney Dis 27 : 394-401, 1996

27) Block GA, Hulbert-Shearon TE, Levin NW, Port FK : Association of serum phosphorus and calcium $\mathrm{x}$ phosphate product with mortality risk in chronic hemodialysis patients: A national study. Am J 
Kidney Dis $31: 607-617,1998$

28) Levin NW, Hulbert-Shearon TE, Strawderman RL, Port FK: Which causes of death are related to hyperphosphatemia in hemodialysis (HD) patients? J Am Soc Nephrol 9 : 217 A (Abstract), 1998

29) Foley RN, Parfrey PS, Harnett JD, Kent GM, Hu L, O'Dea R, Murray DC, Barre PE: Hypocalcemia, morbidity, and mortality in end-stage renal disease.
Am J Nephrol 16 : 386-393, 1996

30) Meyer DB, Levey AS : Controlling the epidemic of cardiovascular disease in chronic renal disease: Report from the National Kidney Foundation Task Force on cardiovascular disease. J Am Soc Nephrol 9:S31-S42, 1998

31) Data from USRDS Case-Mix Adequacy Study. Am J Kidney Dis $20: 32-38,1992$ 